\title{
Concentration of Biogenic Amines in Rainbow Trout (Oncorhynchus mykiss) Preserved in Ice and its Relationship with Physicochemical Parameters of Quality
}

Bruna Leal Rodrigues ${ }^{1}$, Thiago Silveira Alvares², Marion Pereira da Costa ${ }^{1}$, Guilherme Sicca Lopes Sampaio¹, César Aquiles Lázaro de la Torre $^{1}$, Eliane Teixeira Mársico ${ }^{1}$ and Carlos Adam Conte Júnior ${ }^{1 *}$

${ }^{1}$ Laboratory of Physicochemical Control, Department of Food Technology, Fluminense Federal University, Niterói, Brazil

${ }^{2}$ Chemistry Institute, Federal University of Rio de Janeiro, Rio de Janeiro, Brazil

\begin{abstract}
Biogenic amines are formed as a result of amino acid decarboxylation and are linked to food deterioration. Analysis of these metabolites may be of great importance to determine food quality. The aim of this study was to quantify the biogenic amines (putrescine and cadaverine), and evaluate the physicochemical parameters $(\mathrm{pH}$, ammonia and total volatile bases) of rainbow trout meat (Oncorhynchus mykiss). Fifteen samples were packed in ice and transported in a Styrofoam container to the laboratory. Analyses were performed daily until the 15th day of storage. Biogenic amines concentrations and $\mathrm{pH}$ increased significantly throughout the storage period. No significant differences were observed in total volatile bases values over the time. Ammonia was detected after the 11th day of storage. Based on these results, cadaverine and putrescine may be used as a quality index of rainbow trout; however, total volatile bases may not be adequate parameter for this matrix.
\end{abstract}

Keywords: Physicochemical parameters; Biogenic amines; Quality index; Rainbow trout

\section{Introduction}

Fish and fishery products have played an important role in the human diet due to their high nutritional quality [1]; however, the chemical composition, high water activity, easily oxidized fat content, and $\mathrm{pH}$ close to neutral, accelerate its deterioration by promoting the development of the natural microbiota in this food matrix [2,3]. The deterioration occurs as a result of enzymatic and microbial activity, resulting in the production of different metabolites, which can lead to loss of product quality and can serve as quality indicators of the raw material $[4,5]$.

The total volatile bases (monomethylamine, dimethylamine, trimethylamine, ammonia) are nitrogenous compounds originated from the degradation of some compounds in fish (amino acids and nucleotides) during the deterioration process $[6,7]$. The determination of total volatile bases (TVB) is one of the most widely used for assessing fish quality [6].

In freshwater fish, ammonia is considered a good indicator for evaluating the quality index, since it is the main compound of the group of substances evaluated in the analysis of TVB in these species [8]. Another indicator also widely used to evaluate the degradation process of fish is the hydrogen potential $(\mathrm{pH})$. During the decaying process, there is the formation of alkaline compounds such as ammonia and amines, which accumulate in the muscle, increasing the muscle $\mathrm{pH}$ values [9].

Biogenic amines are formed as a result of amino acid decarboxylation, which is linked to the existence of spoilage bacteria in the food matrix $[6,10,11]$. Studies have reported that the biogenic amines, especially putrescine and cadaverine, can be considered good parameters for assessing the quality and the deterioration rate of various food matrices, including fish $[3,11-15]$. The development of analytical methods, faster than microbiological ones, for the identification and quantification of biogenic amines is very important to determine fish freshness $[3,6]$. Currently, chromatographic techniques offer a great advantage, since they ensure accurate measurements and allow for the simultaneous analysis of several biogenic amines in fish and fishery products $[16,17]$. Among the chromatographic techniques, high-performance liquid chromatography (HPLC) is being widely used because of its sensitivity and reliability [18].

Due to the fact that there is limited scientific evidence demonstrating the effectiveness of biogenic amines as quality indicators of trout, and considering that rainbow trout (Oncorhynchus mykiss) is one of the main commercial aquaculture species produced and marketed worldwide [19], this study was conducted with the purpose of evaluating the use of biogenic amines and physicochemical parameters for quality assessment.

\section{Materials and Methods}

\section{Sampling}

Fifteen fresh rainbow trout (Oncorhynchus mykiss) specimens were obtained from the Trutas da Serrinha Company located in Itatiaia, a region of the Serra da Mantiqueira, in the state of Rio de Janeiro, Brazil. The samples were packed in ice $\left(0 \pm 1^{\circ} \mathrm{C}\right)$ and transported in a styrofoam container to the laboratory. The filet was obtained in sterile conditions, and all instruments used for filets dissection were previously sterilized.

*Corresponding author: Dr. Carlos Adam Conte Junior, Laboratory of Physicochemical Control, Department of Food Technology, Fluminense Federal University, Rua Vital Brazil Filho, 64, Santa Rosa Niterói, Rio de Janeiro, Brazil, Tel: 55-21-2629-9545; Fax: 55-21-2629-9541; E-mail: mtaconte@vm.uff.br

Received December 23, 2012; Accepted January 23, 2013; Published February 03, 2013

Citation: Rodrigues BL, Alvares TS, da Costa MP, Lopes Sampaio GS, de la Torre CAL, et al. (2013) Concentration of Biogenic Amines in Rainbow Trout (Oncorhynchus mykiss) Preserved in Ice and its Relationship with Physicochemica Parameters of Quality. J Aquac Res Development 4: 174 doi:10.4172/21559546.1000174

Copyright: (c) 2013 Rodrigues BL, et al. This is an open-access article distributed under the terms of the Creative Commons Attribution License, which permits unrestricted use, distribution, and reproduction in any medium, provided the original author and source are credited. 
Citation: Rodrigues BL, Alvares TS, da Costa MP, Lopes Sampaio GS, de la Torre CAL, et al. (2013) Concentration of Biogenic Amines in Rainbow Trout (Oncorhynchus mykiss) Preserved in Ice and its Relationship with Physicochemical Parameters of Quality. J Aquac Res Development 4: 174 doi:10.4172/2155-9546.1000174

Page 2 of 4

The samples were analyzed daily until the $15^{\text {th }}$ day of storage (Figure 1). All analyses were performed in duplicate.

\section{Physicochemical analyses}

$\mathrm{pH}, \mathrm{TVB}$ and ammonia parameters were determined in order to evaluate the state of fish freshness during storage at $0 \pm 1^{\circ} \mathrm{C}$. For the analysis of $\mathrm{pH}$ and TVB, potentiometric and microdiffusion methods were used, respectively Conte-Júnior et al. and Conway and Byrne $[20,21]$. The qualitative determination of ammonia was performed by using mercuric iodide, potassium iodide, sodium hydroxide solutions and water (Nessler reagent).

\section{Biogenic amines quantification}

The biogenic amines, putrescine and cadaverine, were assayed by High- Performance Liquid Chromatography (HPLC). Briefly, $5 \mathrm{~mL}$ of perchloric acid (5\%) were added to $5 \mathrm{~g}$ of sample and kept 1 hour under refrigeration condition $\left(4 \pm 2^{\circ} \mathrm{C}\right)$ with periodic stirring. Subsequently the solution was centrifuged and filtered through Whatman filter paper No 1 , followed by the addition of $2 \mathrm{~N}$ sodium hydroxide to reach $\mathrm{pH}>6$. In the next step, the homogenized solution was kept in an ice bath for 20 minutes and filtered a second time, with the subsequent addition of $2 \mathrm{~N}$ sodium hydroxide to reach $\mathrm{pH}>12$ [22]. Under these circumstances the solution was derivatized with the addition of $40 \mu \mathrm{L}$ of benzoyl chloride, homogenized for $15 \mathrm{~s}$ and left to stand at room temperature for $20 \mathrm{~min}$. Thereafter, $1 \mathrm{~mL}$ of diethyl ether was added and the supernatant was removed. The resulting sample was evaporated in a stream of nitrogen to be finally resuspended with $500 \mu \mathrm{L}$ of mobile phase (acetonitrile: $\mathrm{H}_{2} \mathrm{O} ; 42: 58 ; \mathrm{v}$ : v) [23]. $20 \mu \mathrm{L}$ of sample were injected into HPLC device coupled with UV detector; the flow rate was set at $1 \mathrm{~mL} \mathrm{~min}^{-1}$. For the separation of the amine, a Teknokroma column, TR-016057 N26243 Tracer Extrasil ODS2 $(15 \times 0.46 \mathrm{~cm}$, id. $5 \mu \mathrm{m})$ and a Supelco precolumn, Ascentis C18 $(2 \times 0.40 \mathrm{~cm}$, id. $5 \mu \mathrm{m})$ were used.

\section{Statistical analysis}

The one-way ANOVA was performed to identify differences between biogenic amines (putrescine and cadaverine) and physicochemical parameters (TVB and $\mathrm{pH}$ ) over the 15-day period of storage. When a significant $F$ was found, additional post hoc tests with Bonferroni adjustment were performed. For the interpretation of result all the data obtained (from day 1 to day 15) were divided into three periods: Time 1 (T1)-analysis of the first five days of storage; Time 2 (T2)-analysis of the subsequent five days; Time 3 (T3)-analysis of the last five days of storage. Based on previous studies $[11,14,24]$, no significant changes should occur in the biogenic amines concentrations and $\mathrm{pH}$ values at Time 1.

Statistical significance was set at the 0.05 level of confidence. All analyses were performed using a commercially available statistical package (GraphPad Prism version 5.00 for Windows, GraphPad Software, San Diego, California, USA).

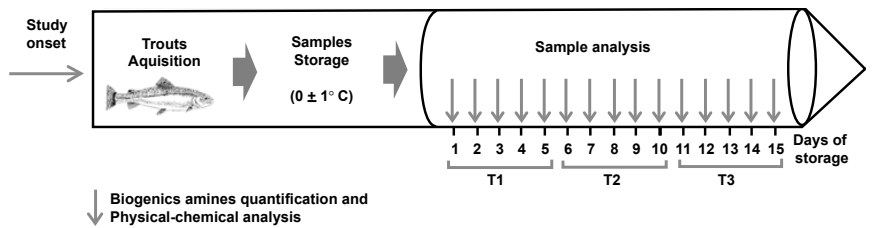

Figure 1: Experimental design of the study.

\section{Results and Discussion}

Recent studies do not report the use of quality physicochemical analyses that are considered simple and fast, and they have also not associated these analyses with biogenic amine concentrations to evaluate the quality of rainbow trout (Oncorhynchus mykiss). Therefore, the present study was designed to investigate the potential use of biogenic amines and physicochemical parameters-such as TVB, ammonia and $\mathrm{pH}$-as a quality index for this species of fish. Overall, the major finding of the study was that the concentrations of the biogenic amine, putrescine and cadaverine, increased significantly-together with a significant increase in $\mathrm{pH}$-over the 15-day storage period and the presence of ammonia was observed only after the 11th day of storage. No significant difference was observed in TVB values during the 15 days of storage.

Changes in TVB and $\mathrm{pH}$ values over the period of the storage are shown in table 1 . There was no significant difference in TVB values throughout the 15 days of storage. A significant increase in $\mathrm{pH}$ was observed in T3 as compared to T1. The presence of ammonia was observed only after the $11^{\text {th }}$ day of storage.

The changes in cadaverine and putrescine concentrations over the days of storage are presented in figures 2 and 3 , respectively. There was a

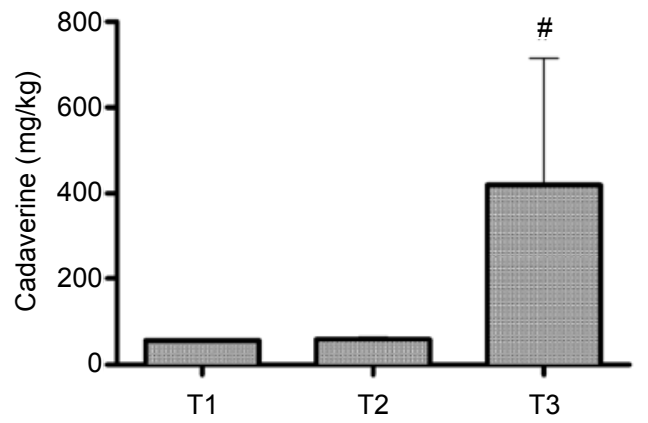

$T 1=a n a l y s i s$ of the first five days of storage; $T 2=a n a l y s i s$ of the subsequent five days; T3=analysis of the last five days of storage. \#Significantly different from T1 and T2.

Figure 2: Cadaverine concentrations $(\mathrm{mg} / \mathrm{kg}$ ) over the period of storage.

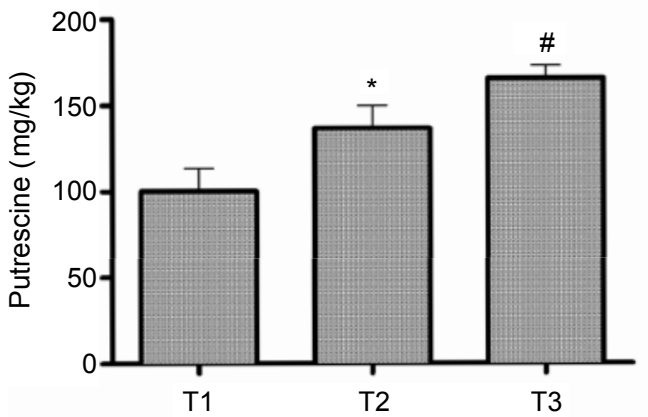

$T 1=a n a l y s i s$ of the first five days of storage; $T 2=a n a l y s i s$ of the subsequent five days; T3=analysis of the last five days of storage. \#Significantly different from T1 and T2. *Significantly different from T1

Figure 3: Putrescine concentrations $(\mathrm{mg} / \mathrm{kg})$ over the period of storage. 
Citation: Rodrigues BL, Alvares TS, da Costa MP, Lopes Sampaio GS, de la Torre CAL, et al. (2013) Concentration of Biogenic Amines in Rainbow Trout (Oncorhynchus mykiss) Preserved in Ice and its Relationship with Physicochemical Parameters of Quality. J Aquac Res Development 4: 174 doi:10.4172/2155-9546.1000174

significant increase in putrescine (T1: $100.17 \pm 13.28 \mathrm{mg} / \mathrm{kg}$; T2: 136.53 $\pm 13.28 \mathrm{mg} / \mathrm{kg}$; T3: $165.62 \pm 7.27 \mathrm{mg} / \mathrm{kg})$ and cadaverine $(\mathrm{T} 1: 56.49 \pm$ $0 \mathrm{mg} / \mathrm{kg}$; T2: $59.22 \pm 4.97 \mathrm{mg} / \mathrm{kg}$; T3: $419.75 \pm 295.44 \mathrm{mg} / \mathrm{kg}$ ) over the storage period.

According to EC Decision 95/149, there is no maximum limit for TVB; however, the limit was fixed to $25 \mathrm{mg} \mathrm{N} / 100 \mathrm{~g}$ in rainbow trout Gimenez et al. [25,26]. Although the present values at the end of storage period were below the limit suggested by Gimenez et al. the fish was in an evident state of sensorial deterioration, which had gone undetected by TVB analysis [26]

The compounds that form TVB are present in varying concentrations in muscle according to the kind of fish [7]. Unlike marine fish, freshwater fish generally have negligible values of trimethylamine oxide. Low levels of trimethylamine and the presence of ammonia are the main compounds that form part of TVB. Due to the low trimethylamine formation, the TVB concentration in freshwater fish species remains low during storage $[8,27]$. In addition, Morishita et al. reported that factors such as age, location and method of cultivation may influence the non-protein nitrogen compound content in the fish muscle, which may influence the TVB levels [28].

In the present study the TVB determination was not considered a good parameter for evaluating the quality index, since the values observed in this analysis did not even change at the end of storage period (Table 1) when the fish reached a state of deterioration (Figures 2 and 3). Other studies have confirmed the present results, demonstrating that TVB is not a good parameter for evaluating the quality index of freshwater fish $[24,27]$. Therefore, TVB may be considered an uncertain and unreliable decay index for freshwater fish.

Regarding ammonia, there was a correlation with the state of sensorial deterioration, since it was detected after the $11^{\text {th }}$ day of storage in the samples. Ammonia is the main compound belonging to this set of volatile bases in freshwater fish species. This analysis is therefore considered satisfactory for evaluating the process of protein degradation; hence it may be used to determine the quality index on these fish species [8].

The $\mathrm{pH}$ values increased continuously over the storage period, reaching higher values in $\mathrm{T} 3(6.77 \pm 0.13)$. This increase was due to the production of basic compounds formed during the autolytic changes [6]. According to Rodriguez et al. the accumulation of alkaline metabolites, such as amines, promotes an increase in muscle $\mathrm{pH}$, indicating a deterioration process [9].

When analyzing the results of biogenic amines, the putrescine and cadaverine concentrations increased significantly throughout the storage period. The behavior of these amines in trout flesh was also observed by other researchers $[11,15]$. Studying the biochemical changes in rainbow trout stored for 12 days, Rodriguez et al. observed an increase of putrescine while cadaverine was detected only after 9 days of storage [11]. The authors suggest that the presence of cadaverine

\begin{tabular}{|l|l|l|l|}
\hline & T1 & T2 & T3 \\
\hline $\begin{array}{l}\text { TVB } \\
(\mathrm{mg} \mathrm{N} / 100 \mathrm{~g})\end{array}$ & $9.30 \pm 0.58$ & $9.07 \pm 1.19$ & $9.07 \pm 0.0$ \\
\hline $\mathrm{pH}$ & $6.47 \pm 0.19$ & $6.73 \pm 0.09$ & $6.77 \pm 0.13^{*}$ \\
\hline
\end{tabular}

$\mathrm{T} 1=$ analysis of the first five days of storage; $T 2=a n a l y s i s$ of the subsequent five days; T3=analysis of the last five days of storage.

*Significantly different from $\mathrm{T} 1$ (only $\mathrm{pH} ; \mathrm{P}<0.05$ ).

Table 1: Mean and standard deviation values for total volatile basis (TVB) and hydrogen potential $(\mathrm{pH})$ over the period of storage. may serve as an indicator of muscle change, which is caused by increased activity of microorganisms. Furthermore, putrescine may be an indicator of premature muscle autolytic degradation, since it is formed during the first days of storage.

According Dawood et al. the rapid formation of putrescine in fish is due to high enzymatic activity (due to the microflora contaminant) that promotes both the decarboxylation of glutamic acid and arginine and the synthesis of ornithine, which results in putrescine formation [12]. The authors suggest that putrescine and cadaverine may be reliable indicators of fish spoilage. Likewise, Rezaei et al. studying the presence of biogenic amines in rainbow trout stored for 18 days, observed an increase of amines during the storage period and suggested that monitoring the putrescine levels may serve as an index to evaluate the freshness of rainbow trout [15].

According to Gram and Dalgaard and Halász et al. the increase and the formation of these amines is related to the bacterial load present in meat $[3,29]$. Halász et al. observed that the bacteria of the family Enterobacteriaceae are usually implicated in the formation of cadaverine [29]. On the other hand, bacteria of the genus Pseudomonas spp. are responsible for the formation of putrescine.

Other previous studies $[4,15,30-32]$ have demonstrated that the formation of biogenic amines depends on several factors that may alter the concentration of these amines in the food matrix. These factors include: aquaculture conditions, food, fish species, body composition, storage and processing conditions, autolytic interactions, availability of free amino acids, and the presence of decarboxylase-active microorganisms.

Based on the results of the present study, it appears that the biogenic amines, putrescine and cadaverine, may be considered suitable indicators of the degradation process of rainbow trout meat. Furthermore, the presence of ammonia and changes in $\mathrm{pH}$ may be regarded as quality parameters to evaluate this species. Finally, the total volatile bases (TVB) were not useful in assessing the deterioration level of the fish studied.

\section{Acknowledgments}

The authors are thankful for the financial support of the State of Rio de Janeiro Carlos Chagas Filho Research Foundation (FAPERJ), process numbers E-26/111.933/2011, E-26/110.460/2012 and E-26/103.003/2012. BL Rodrigues was supported by the National Council for Scientific and Technological Development (CNPq). Trutas da Serrinha is gratefully acknowledged for providing samples. The authors would like to thank Ricky Toledano for the English revision of the manuscript.

\section{References}

1. Fallah AA, Saei-Dehkordi SS, Nematollahi A (2011) Comparative assessment of proximate composition, physicochemical parameters, fatty acid profile and mineral content in farmed and wild rainbow trout (Oncorhynchus mykiss). Int J Food Sci Tech 46: 767-773.

2. Gram L, Huss HH (1996) Microbiological spoilage of fish and fish products. Int J Food Microbiol 33: 121-137.

3. Gram L, Dalgaard P (2002) Fish spoilage bacteria-problems and solutions. Curr Opin Biotechnol 13: 262-266.

4. Liston J (1980) Microbiology in fishery science. In: Edited by JJ, (eds.) Advances in fish science and technology. Fishing News Books. England: Surrey.

5. Arashisar S, Hisar O, Kaya M, Yanik T (2004) Effects of modified atmosphere and vacuum packaging on microbiological and chemical properties of rainbow trout (Oncorhynchus mykiss) fillets. Int J Food Microbiol 97: 209-214.

6. Huss HH (1995) Quality and quality changes in freshwater fish. Fisheries 
Citation: Rodrigues BL, Alvares TS, da Costa MP, Lopes Sampaio GS, de la Torre CAL, et al. (2013) Concentration of Biogenic Amines in Rainbow Trout (Oncorhynchus mykiss) Preserved in Ice and its Relationship with Physicochemical Parameters of Quality. J Aquac Res Development 4: 174 doi:10.4172/2155-9546.1000174

Page 4 of 4

Technical Paper No. 348. Rome: Food and Agriculture Organization (FAO) of United Nations.

7. Giannini DH (2003) Determinación de nitrógeno básico volátil (NBV) em pescado: Consideraciones Generales. Alimentaria 40: 49-54.

8. Zaitsev V, Kizevetter I, Lagunov L, Makarova T, Minder L, et al. (1969) Caracteristics of fish as a raw material for industry. In: Fish curing and processing. Moscou.

9. Rodríguez O, Losada V, Aubourg SP, Barros-Velázquez J (2004) Enhanced shelf-life of chilled European hake (Merluccius merluccius) stored in slurry ice as determined by sensory analysis and assessment of microbiological activity. Food Res Int 37: 749-757.

10. Mietz JL, Karmas E (1977) Chemical quality index of canned tuna as determined by high-pressure liquid chromatography. J Food Sci 42: 155-158.

11. Rodriguez CJ, Besteiro I, Pascual C (1999) Biochemical changes in freshwater rainbow trout (Oncorhynchus mykiss) during chilled storage. J Sci Food Agric 79: $1473-1480$

12. Dawood AA, Karkalas J, Roy RN, Williams CS (1988) The occurrence of nonvolatile amines in chilled-stored rainbow trout (Salmo irideus). Food Chem 27: $33-45$

13. Krizek M, Pavlicek T, Vacha F (2002) Formation of selected biogenic amines in carp meat. J Sci Food Agric 82: 1088-1093.

14. Katikou P, Georgantelis D, Paleologos EK, Ambrosiadis I, Kontominas MG (2006) Relation of biogenic amines' formation with microbiological and sensory attributes in lactobacillus-inoculated vacuum-packed rainbow trout (Oncorhynchus mykiss) fillets. J Agric Food Chem 54: 4277-4283.

15. Rezaei M, Montazeri N, Langrudi HE, Mokhayer B, Parviz M, et al. (2007) The biogenic amines and bacterial changes of farmed rainbow trout (Oncorhynchus mykiss) stored in ice. Food Chem 103: 150-154.

16. Hwang DF, Chang SH, Shiua CY, Chai TJ (1997) High-performance liquid chromatogramphic determination of biogenic amines in fish implicated in food poisoning. J Chromatogr B Biomed Sci Appl 693: 23-29.

17. Cinquina AL, Calì A, Longo F, Santis L, Severoni A, et al. (2004) Determination of biogenic amines in fish tissues by ion-exchange chromatography with conductivity detection. J Chromatogr A 1032: 73-77.

18. Ozogul F, Taylor KDA, Quantick P, Ozogul Y (2002) Biogenic amines formation in Atlantic herring (Clupea harengus) stored under modified atmosphere packaging using a rapid HPLC method. Int J Food Sci Tech 37: 515-522.

19. Coloso R M, King K, Fletcher JW, Weis P, Werner A, et al. (2003) Dietary P regulates phosphate transporter expression, phosphatase activity, and effluent P partitioning in trout culture. J Comp Physiol B 173: 519-530.

20. Conte Junior CA, Peixoto BTM, Lopes MM, Franco RM, Freitas MQ, et al. (2010) Effect of modified atmosphere packaging on the growth/survival of Yersinia enterocolitica and natural flora on fresh poultry sausage. In: MéndezVilas A (ed.) Current Research, Technology and Education Topics in Applied Microbiology and Microbial Biotechnology (2ndedn), spain.

21. Conway EJ, Byrne A(1933) An absorption apparatus for the micro-determination of certain volatile substances: The micro-determination of ammonia. Biochem J 27: 419-429.

22. Rodríguez SC, López B, Chaves AR (2001) Effect of different treatments on the evolution of polyamines during refrigerated storage of eggplants. J Agric Food Chem 49: 4700-4705.

23. Mei YH (1994) A sensitive and fast method for the determination of polyamines in biological samples. Benzoyl chloride pre-column derivatization highperformance liquid chromatography. J Liq Chrom 17: 2413-2418.

24. Chytiri S, Chouliara I, Savvaidis IN, Kontominas MG (2004) Microbiological chemical and sensory assessment of iced whole and filleted aquacultured rainbow trout. Food Microbiology 21: 157-165.
25. European Union (1995) Commission decision 95/149/EC, 8, March 1995. Off J Eur Comm. L97, 84-87.

26. Gimenez B, Roncales P, Beltran JA (2002) Modified atmosphere packaging of filleted rainbow trout. J Sci Food Agric 84: 1154-1159.

27. Scherer R, Augusti PR, Bochi VC, Steffens C, Fries LLM, et al. (2006) Chemical and microbiological quality of grass carp (Ctenopharyngodon idella) slaughtered by different methods. Food Chem 99: 136-142.

28. Morishita T, Uno K, Araki T, Takahashi T (1989) Comparison of the amounts of extractive nitrogenous constituents in the meats of cultured red sea bream of different localities and culture methods and those of wild fish. Nippon Suisan Gakk 55: 1565-1573.

29. Halász A, Baráth Á, Simon-Sarkadi L, Holzapfel W (1994) Biogenic amines and their production by microorganisms in food. Trends Food Sci Technol 5: 42-49.

30. Shahidi $F(1994)$ The chemistry processing technology and quality of seafoodsan overview. In: Shahidi F, Botta JR, (eds.). Seafoods chemistry, processing technology and quality of seafoods. Great Britain.

31. Bodmer S, Imark C, Kneubuhl M (1999) Biogenic amines in foods: histamzine and food processing. Inflamm Res 48: 296-300.

32. Krizek M, Vacha F, Vorlova L, Lukasova J, Cupakova S (2004) Biogenic amines in vacuum-packed and non-vacuum packed flesh of Carp (Cyprinus carpio) stored at different temperatures. Food Chem 88: 185-191. 